\title{
Strategy for the Production of Smartphone Reward Applications Applying the Technology Acceptance Model
}

\author{
Seung-Yeob Yu
}

\begin{abstract}
This study was conducted to propose a smartphone reward application production strategy. The covariance structure analysis was used for the hypothesis test of this study. The results of the hypothesis testing are as follows. First, the financial benefits and psychological satisfaction benefits of smartphone reward applications have a statistically significant influence on perceived ease-of-use. In contrast, information acquisition benefits had a significantly negative impact on perceived ease-of-use. Second, psychological satisfaction and extra time utilization benefit of smartphone reward application exert a significant effect on perceived usefulness. Third, the perceived ease-of-use of smartphone reward applications has a significant effect on perceived usefulness. Fourth, perceived usefulness of smartphone reward application has a significant effect on persistent intention to use. With the results of this study, we propose useful guidelines for making smartphone reward applications.
\end{abstract}

Keywords : Smartphone, Smartphone application Benefit factor, Technology Acceptance Model

\section{INTRODUCTION}

Since the spread of smartphones in 2009, its influence has been widening in all aspects of our lives, especially in the advertising and marketing fields, which are attracting attention as new media and are making a big change in the mobile advertising market. One of the most distinctive features of smart phones is that they can be installed and operated by downloading the desired mobile application. Here, a mobile application means an application program implemented in a mobile phone or a portable terminal[1]. The emergence of applications based on smartphones enabled us to communicate at all times regardless of time and place between consumers and sellers, and thus the concept of time and place separation between existing buyers and sellers has become scarce.

Therefore, such applications will be a major competitive factor in the smartphone market, and smartphone users are also expected to consider the performance of handsets as well as the quantity and quality of applications that can be used in handsets. In 2009, smartphone applications accounted for only $44 \%$ of the total market. However, the market grew at a CAGR of $61 \%$ between 2010 and 2015, reaching 15.77

Revised Manuscript Received on July 22, 2019.

Seung-Yeob, Yu, Department of Advertising and Public Relations, Namseoul University, Cheonan, Republic Korea. Email: ysyeob@ hanmail. net billion units in 2015, accounting for $85.4 \%$. The smartphone application market is expected to account for the majority of the total mobile application market[2] .

As such, the mobile advertising market is rapidly evolving through smartphones, but research on this emerging market is very limited. Especially, very few studies on mobile applications and/or specific applications have been reported in the literature. The current paper proposes a reward application that is emerging in mobile advertising market. We are hopeful that the results of this study might help expand the research of smartphone applications and ultimately propose an effective smartphone reward application production strategy.

What are the benefits of using benefit factors to activate smartphone reward applications? With the results of analysis, the present paper presents a smartphone reward application production strategy. In order to solve this research purpose, first, we want to confirm what beneficiary factors users who use smartphone reward application perceive. Second, how will benefit factors of smartphone reward application affect perceived usefulness? Third, we examine whether the benefits of smartphone reward applications will affect perceived ease-of-use. Fourth, it will be tested whether the perceived ease-of-use of smartphone reward applications affects perceived usefulness. Fifth, we ask if the perceived ease-of-use of smartphone reward applications affects the intention of continuous use. Finally, we will examine whether the perceived usefulness of smartphone reward applications will affect intention of continuous use. With the results of this research, we will propose some implications for smartphone reward application makers considering factors to consider when making smartphone reward applications.

The Technology Acceptance Model (TAM) developed by Davis can account for users' acceptance of information technology acceptance of new information technologies[3]. This model was first introduced in the field of MIS (Management Information System) related to information technology and proposed to investigate the individual 's reaction to computer - based technology acceptance of users in the organization. However, while applying various variable adjustments according to the analysis subjects of general users, it is now the most generalized theoretical basis for identifying the acceptance process of the audience in the study of new media such as 
interactive TV advertisement, mobile advertisement and DMB.

This theory of acceptance follows Fishbein \& Ajzen's Theory of Reasoned Action (TRA) [4], which argues that individual behavior is triggered by behavioral intention, and that the intention of action depends on the attitude and subjective norm of individual behavior. Also, this theory develops factors suggested by Rogers 's innovation diffusion theory[5] as a determinant of attitudes toward adoption of new media or technologies, and suggests perceived usefulness (PU) and perceived ease-of-use (PEU). Perceived ease-of-use refers to how much a user believes that the technology can be used without worrying about physical and psychological hassles. On the other hand, perceived usefulness indicates a degree of belief that better performance can be achieved through acceptance of the technology[3]. As the perceived ease of use improves, the effort required to accommodate the technology is reduced, and the more cognitive and physical resources that can be put into the task[3], [6]. For example, Davis who first introduced the technology acceptance model, has found that belief in perceived usefulness rises as perceived ease-of-use improves. Featherman \& Pavlou [7]and Kamarulzaman [8]have demonstrated that the positive effects of PEU are also being reproduced in the context of online e-commerce. In addition, Cheong and Park[9], Hong, Thong, and Tam[10] and Lu, Yao, and $\mathrm{Yu}$ [11] have confirmed the positive impact of this ease-of-use on the mobile-based wireless Internet service context. In addition, Nysveen, Pedersen, and Thorbjornsen[12] have demonstrated a positive impact on the usability of this ease-of-use in the context of mobile services such as short message/text services (SMS), payment, and/or games.

Therefore, the technology acceptance model exhibits that the perceived usefulness and ease-of-use of the audience constitute the causal relationship with the attitudes of the users and influence the behavioral intentions of the users and determine the actual usage behavior. In this context, the usefulness means the degree of expectation that the audience will be able to increase productivity by using new technology, and the ease-of-use shows how much the audience expects to use the new technology without much effort [3]. Applying the concept of PEU to the use of smartphones is a variable that represents a variety of forms that are easier, faster, and more comfortable for the user to perceive by using a smartphone. In this study, we investigate how the perceived ease-of-use of smartphone reward application users affects perceived usefulness and the relevance that affects the intention of continuous use of reward application. The model was set up and examined. In recent years, Verkasalo et al. [13], Kim Soo-in, Lee Sang-hoon and Hwang, Hyeon-suk studied the factors influencing users' intention to use by changing the variables and presented a slightly modified version of the technology acceptance model [14]. Kim, Sung-gae analyzed the external variables such as network externality, instant connectivity, and job suitability related to smartphone acceptance[15]. Park, In-gon and Shin, Dong-hee presented the subdivided factors of perceived ease of use through factors such as quick connectivity (information retrieval and information acquisition), problem solving ability and shooting /screen[16].

On the other hand, perceived usefulness is perceived that smartphone users can benefit from their personal life and work thanks to using smartphone and as a result their performance can be improved. Many empirical studies have been performed, using the TAM, and it has been reported that perceived usefulness is one of the two factors that exerts positive effect on PEU and intention to use. At the same time, it has been demonstrated in the mobile field that perceived usefulness has more positive effect than perceived ease-of-use on intention to use [17, 18]. It is agreed in aomost all studies that the perceived usefulness of related to smartphones has a positive effect on intention to use [14]. In particular, we have confirmed, utlizing the TAM, that the perceived usefulness has a statistically significant effect on the intention to use the smartphone reward application [19]. Therefore, the current paper bases its research model on several previous studies related to the existing TAM. We want to identify the causal relationship between the benefit factors experienced and the perceived attributes (PEU and perceived usefulness) when using smartphone reward applications.

In this study, what are the benefits of using smartphone reward applications for smartphone users? This question confirms the benefits of smartphone reward applications. We apply these benefit factors to the technology acceptance model [20] to investigate the relationship between variables. Therefore, we set the following hypotheses. A research model that combines the above five hypotheses is illustrated below in <Figure 1>.

Hypothesis 1: Smartphone reward application benefit factors (monetary benefit, psychological satisfaction benefit, information acquisition benefit, and leisure time benefit) will affect perceived ease-of-use.

Hypothesis 2: Smartphone reward application benefit factors (monetary benefit, psychological satisfaction benefit, information acquisition benefit, and leisure time benefit) will affect perceived usefulness.

Hypothesis 3: Perceived ease of use of smartphone reward applications will affect perceived usefulness.

Hypothesis 4: Perceived Ease of Use of smartphone reward applications will affect the intention of continuous use.

Hypothesis 5: Perceived usefulness of smartphone reward applications will affect the intention of continuous use. 


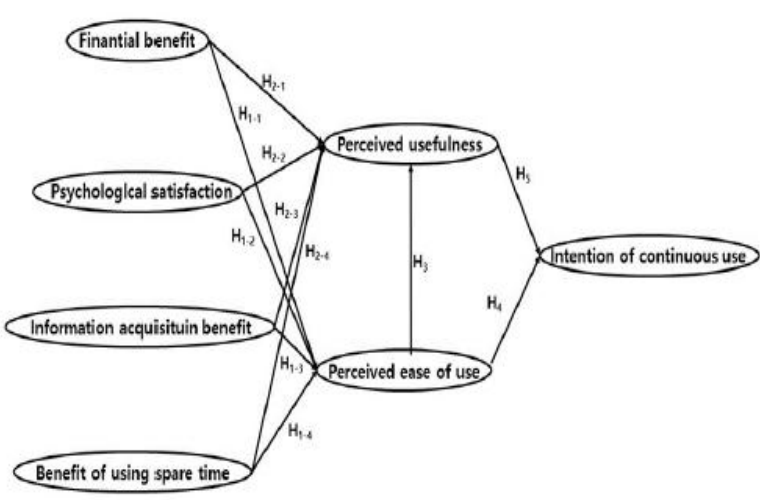

Figure 1: Research model

\section{MATERIALS AND METHODS}

\section{A. Subjects}

Author (s) can send paper in the given email address of the journal. There are two email address. It is compulsory to send paper in both email address.

\section{B. Operational Definition}

Up to now, the definition of reward applications has been summarized only as a representative means of Apptech through Naver's encyclopedia, the discussion on this is very scarce. Even in academia and in practice, there is no definite definition. Here, "apptech" is a term used to refer to a new technology trend that makes money by making use of smartphone apps as a compound word for apps and finance. (Naver's Encyclopedia, Feb. 2013). Therefore, operational definition of this is considered to be a very important issue in this study. A reward application is a term made up of a combination of reward and application. In this study, we define the definition of reward application as follows. The reward application is defined as "a mobile advertising application that is implemented in a form that compensates for the use of cash as the cash point is accumulated as a reward for watching advertisements or solving quizzes through applications (or apps) on the smartphone"[21]. Based on this operational definition, this study selected two applications of Ad Latte and Cathy Slide which are forming the most users in the present study as a reward application.

\section{Measurement Tools}

\section{Reward Application Benefit Factor Scale}

In this study, the reward application benefit factor is defined as the benefit that the smartphone user experiences or feels while using the reward application [20]. We used the scale of the study by $\mathrm{Yu}$ and Kim [20] to determine the benefits of Smartphone Reward application. Benefit factor scale consisted of 19 items and Likert type scale. Cronbach's alpha $=.891)$, psychological satisfaction (Cronbach's alpha $=$ .851 ), information acquisition (Cronbach's alpha $=.901$ ), and leisure time usage (Cronbach's alpha $=938$ ).

\section{Perceived Ease-of-Use(PEU)}

The term 'perceived attributes of reward applications' refer to both 'perceived ease-of-use and usefulness'. First, the former can be defined as 'the ease of use' that anyone can easily use in reward applications. We used the Davis research scale[3] to determine the ease of use of smartphone reward applications perceived by users. This factor consisted of 5 questions measured on a 5-point Likert scale. Cronbach's alpha $=.898$.

\section{Perceived Usefulness}

The latter factor of usefulness perceived by users is defined as how helpful the reward application is to me [20]. We used the Davis research scale to examine the perceived usefulness of smartphone reward applications. The Perceived Usefulness was composed of 4 items and Likert type 5 point scale. The reliability of the scale was obtained: Cronbach's $\alpha$ $=.917$.

4. Intention of Continuous Use

The intention of continuous use on smartphone reward application is to intentionally intend to continue to use the reward application currently used by smartphone reward application users [19]. We used the scale of Yu's research to determine the intention of continuous use of smartphone reward applications. The perceived ease of use was composed of 4 items and Likert type 5 point scale. The analysis of the reliability the scale found that Cronbach's $\alpha=.960$ was very high.

\section{Data Analysis}

For the hypothesis test of this study, we used covariance structure analysis using AMOS 21.0. Exploratory factor analysis was conducted to examine the benefits of smartphone applications. Cronbach's alpha was calculated to identify the reliability of the scales used in the present research.

\section{RESULTS AND DISSCUSSION}

\section{A. Benefits of Smartphone Reward Application}

An exploratory factor analysis was performed in order to identify the factors related to the benefits and satisfaction experienced by smartphone users using reward applications. Factor rotation method was VARIMAX and Eigen Value 1.0 or higher was used as a factor selection criterion. Below can be found the results of this factor analysis in $\langle$ Table 1$\rangle$. In turn, an exploratory factor analysis was conducted to find out what the benefits of smartphone reward application users are when they use the application. As a result, there are 4 benefit factors of smartphone reward application. The benefits were monetary benefits, psychological gratification benefits, information acquisition benefits, and free time.

\section{B. Hypothesis Testing}

Prior to the hypothesis testing, $\chi 2$ test was conducted to confirm the fit of the study model. RMR, RMSEA, GFI, and AGFI were used as the absolute fit indices. The incremental fit indices were verified using NFI, CFI, and TLI. Based on the above acceptability index, we analyzed the causal relationship between the benefits of smartphone reward application used: perceived ease-of-use, perceived usefulness, 
and intention to use continuously. Table 2 shows the initial and final model fit and identified figures of the analysis Table 1: Validity and Reliability of Measured Variables

\begin{tabular}{|c|c|c|c|c|c|c|}
\hline Item & Factor 1 & Factor 2 & Factor 3 & Factor 4 & Communality & Cronbach $\alpha$ \\
\hline Benefit 6 & .799 & & & & .670 & \multirow{7}{*}{.851} \\
\hline Benefit 7 & .749 & & & & .620 & \\
\hline Benefit 4 & .699 & & & & .613 & \\
\hline Benefit 3 & .695 & & & & .536 & \\
\hline Benefit 5 & .636 & & & & .470 & \\
\hline Benefit 8 & .623 & & & & .497 & \\
\hline Benefit 2 & .543 & & & & .491 & \\
\hline Benefit 14 & & .861 & & & .850 & \multirow{5}{*}{901} \\
\hline Benefit 15 & & .819 & & & .807 & \\
\hline Benefit 16 & & .791 & & & .704 & \\
\hline Benefit 13 & & .781 & & & .728 & \\
\hline Benefit 1 & & .564 & & & .594 & \\
\hline Benefit 11 & & & .892 & & .822 & \multirow{4}{*}{.910} \\
\hline Benefit 10 & & & .861 & & .808 & \\
\hline Benefit 12 & & & .856 & & .798 & \\
\hline Benefit 9 & & & .824 & & .756 & \\
\hline Benefit 18 & & & & .887 & .901 & \multirow{3}{*}{.938} \\
\hline Benefit 19 & & & & .883 & .877 & \\
\hline Benefit 17 & & & & .841 & .864 & \\
\hline Eigen value & 3.92 & 3.56 & 3.32 & 2.61 & - & \\
\hline$\%$ of Variance & 20.64 & 17.71 & 17.45 & 13.75 & - & \\
\hline Cumulative \% & 20.64 & 39.35 & 56.81 & 70.56 & - & \\
\hline
\end{tabular}

Table 2: Comparison of Research Models and the Final Model Fit Indices

\begin{tabular}{|c|c|c|c|c|c|c|c|}
\hline Fit Indices & RMR & RMSEA & GFI & AGFI & NFI & CFI & TLI \\
\hline Research model & .082 & .077 & .783 & .741 & .847 & .902 & .890 \\
\hline Finalized model & .058 & .039 & .906 & .876 & .932 & .980 & .976 \\
\hline Acceptance level & $>.05$ & $<0.8$ & $>90$ & $>.90$ & $>.90$ & $>90$ & $>.90$ \\
\hline
\end{tabular}

Table 3: Results of Testing Hypotheses

\begin{tabular}{|c|c|c|c|c|c|c|c|}
\hline \multicolumn{3}{|c|}{ Channel } & & Estimate & S.E. & C.R. & \multicolumn{1}{|c|}{ Hypothesis } \\
\hline Perceived ease of use & $\leftarrow$ & Financial benefit & .499 & .123 & 4.048 & $* * *$ & H1-1, Accept \\
\hline Perceived ease of use & $\leftarrow$ & Psychological satisfaction & .197 & .059 & 3.318 & $* * *$ & H1-2, Accept \\
\hline Perceived ease of use & $\leftarrow$ & Information acquisition benefit & -.155 & .053 & -2.941 & .003 & H1-3, Accept \\
\hline Perceived ease of use & $\leftarrow$ & Benefit of using spare time & .022 & .043 & .513 & .608 & H1-4, Reject \\
\hline Perceived usefulness & $\leftarrow$ & Financial benefit & .129 & .099 & 1.301 & .193 & H2-1, Reject \\
\hline Perceived usefulness & $\leftarrow$ & Psychological satisfaction & .162 & .053 & 3.037 & .002 & H2-2, Accept \\
\hline Perceived usefulness & $\leftarrow$ & Information acquisition benefit & .010 & .044 & .233 & .816 & H2-3, Reject \\
\hline Perceived usefulness & $\leftarrow$ & Benefit of using spare time & .092 & .038 & 2.451 & .014 & H2-4, Accept \\
\hline Perceived usefulness & $\leftarrow$ & Perceived ease of use & .216 & .106 & 2.036 & .042 & H3, Accept \\
\hline Intention of continuous use & $\leftarrow$ & Perceived usefulness & 2.425 & .311 & 7.792 & $* * *$ & H4, Accept \\
\hline Intention of continuous use & $\leftarrow$ & Perceived ease of use & -.199 & .223 & -.895 & .371 & H5, Reject \\
\hline
\end{tabular}

As a result of Hypothesis 1 , the financial benefits $(\mathrm{t}=$ $4.048, \mathrm{p}<.001)$ and psychological satisfaction $(\mathrm{t}=3.318, \mathrm{p}<$ $.01)$ had a significant impact on perceived ease-of-use. However, the benefits of using spare time $(t=.531, \mathrm{p}>.05)$ did not affect the ease-of-use perceived by users. Therefore, it can be interpreted that it might be effective to provide financial benefits and easy ways of acquiring information and information for enhancing psychological satisfaction in order to increase ease of use when smartphone users use reward applications(see table 3).

As a result of hypothesis 2, psychological satisfaction $(t=$ 3.307, $\mathrm{p}<.001)$ and benefit of leisure time $(\mathrm{t}=2.451, \mathrm{p}<.01)$ exert a significant influence on perceived usefulness, respectively. However, financial benefits $(t=1.301, p>.05)$ and information acquisition benefits $(\mathrm{t}=.233$, $\mathrm{p}>.05)$ did not affect the usefulness perceived by users. Therefore, it is necessary to emphasize that we should improve the psychological satisfaction of user's use of applications and use of spare time in order to improve the usability of applications when using reward applications.

As a result of Hypothesis 3, the PEU of smartphone reward application $(\mathrm{t}=2.036, \mathrm{p}<.05)$ has a positive effect on the usefulness perceived by users. These results are interpreted as supporting the model of TAM. As a result of Hypothesis 4, the perceived ease-of-use of smartphone reward applications $(t=-.895, p>.05)$ did not significantly affect the intention of continuous use. As a result of Hypothesis 5, the perceived ease-of-use of smartphone reward applications $(t=7.792, p$ $<.001)$ had a significant influence on the intention to use continuously. Therefore, 
these results suggest that it is necessary to increase the usability of the application directly in order to increase the continuity of use of the smartphone reward application.
Table 3 shows the hypothesis verification tests.

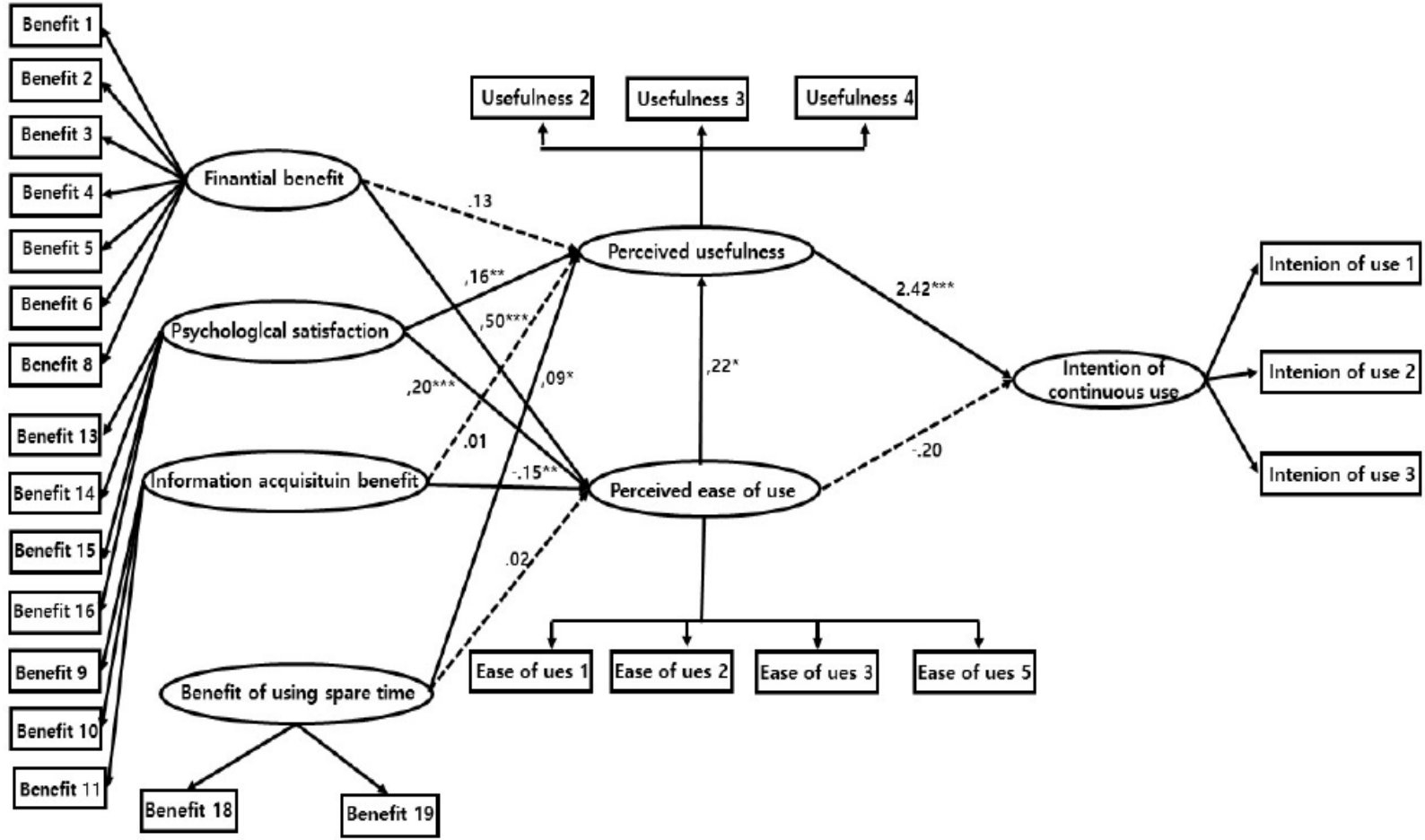

※ A solid line is an adopted hypothesis: a dotted line a rejected one

Figure 2: Finalized Research Model

\section{CONCLUSION}

Adopting the technology acceptance model, the current research succeeded in confirming the significant effect of the benefit factors of smartphone reward applications on users' intention to use continuously. The findings of this research lead us to propose some useful guidelines for smartphone reward applications.

The results of the hypothesis test are summarized as follows. First, it was found that the beneficiary factors of the smartphone reward application influence the ease of use perceived by users, and the financial benefit factors have a statistically significant positive impact on the perceived ease-of-use. Therefore, when creating a smartphone reward application, the financial benefit factor must be considered. In addition, there is a need to design the application so that the financial benefit of using the application is very easy to perceive. Psychological satisfaction benefit factors exert a statistically significant positive influence on ease-of-use percived by users. Therefore, psychological satisfaction benefit factor should be considered important when making smart phone reward application. In addition, it is necessary to search for ways to improve psychological satisfaction of users when designing applications. Also found was a significantly negative effect of information acquisition benefit factors on users' ease-of-use. The more users acquire information in the reward application, the less perceived ease-of-use is interpreted. Therefore, it is necessary to search for ways to acquire appropriate information when designing or making a reward application. Second, as a result of confirming whether there exists a signficant relationship between beneficiary factors of smartphone reward application and perceived usefulness, it was shown that psychological satisfaction benefit factors have a positive effect. Therefore, psychological satisfaction benefits must be taken into account when creating smartphone reward applications. In addition, there is a need to create an application so that psychological satisfaction can be perceived very easily when using an application. Also, the use of spare time plays a significant role in influencing the usefulness perceived by users. In the reward application, it is interpreted that the more users use the reward application by utilizing their own free time, the more useful they perceive the application. Therefore, it can be said that it is effective to utilize storytelling that promotion of reward application is advantageous by utilizing spare time. Third, the ease-of-use of smartphone reward applications perceived by users has a statistically positive effect on perceived ease of use. These results indicate that smartphone reward application developers will find the application useful and easy to design and build. In other words, it is very important to make it easy and easy to use when making smartphone reward application. Fourth, the perceived usefulness of the smartphone reward application has a statistically significant positive effect on the intention to use continuously. Therefore, when creating a smartphone reward

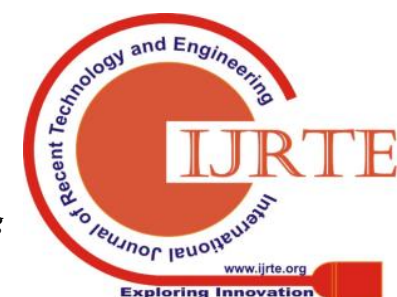


application, it is necessary to encourage users to promote their own reward application as a useful application in everyday life.

This study suggests that there are important implications in the reality that smartphone users are increasing rapidly. We hope that application developers will be able to solve some of the questions that are important points to consider. It is hopeful that the results of this research will be activated for actual smartphone applications.

\section{ACKNOWLEDGMENT}

Funding for this paper was provided by Namseoul University.

\section{REFERENCES}

1. Han PK, Park JS, Jun BH, Kang MG., "A Study on the Factors of Mobile Applications Adoption" The Korea IT \& Service Association, 9(3), 2010 pp. $65-82$.

2. Jung BY., "Trends and Implications of Mobile Content and Application Change in Mobile Environment" Broadcasting communication policy, 22(18), 2010, pp. 37-64.

3. Davis FD., "Perceived usefulness, perceived ease of use, and user acceptance of information technology" MIS quarterly. Sep(1), 1989, pp. 319-40. https://www.jstor.org/stable/249008

4. Fishbein M, Ajzen I., Belief, attitude, intention, and behavior: An introduction to theory and research, 1997.

5. Roser MC., Enabling drug adherence through closed loop monitoring \& communication. United States patent application US 11/698,642. 2007 Jul 26. Fiske ST, Taylor SE. Social cognition. Mcgraw-Hill Book Company; 1991.

6. Carlos Martins Rodrigues Pinho J, Soares AM., "Examining the technology acceptance model in the adoption of social networks" Journal of Research in Interactive Marketing, Jun(7), 2011, pp. 116-129. https://doi.org/10.1108/17505931111187767

7. Featherman MS, Pavlou PA., "Predicting e-services adoption: a perceived risk facets perspective" International journal of human-computer studies, 59(4), 2003, pp. 451-474 https://doi.org/10.1016/s1071-5819(03)00111-3

8. Kamarulzaman Y., "Adoption of travel e-shopping in the UK. International" Journal of Retail \& Distribution Management, 35(9), 2007, pp. 703-719. https://doi.org/10.1108/09590550710773255

9. Cheong JH, Park MC, "Mobile internet acceptance in Korea" Internet research, 15(2), 2005, pp. 125-140.

10. Hong S, Thong JY., Tam KY., "Understanding continued information technology usage behavior: A comparison of three models in the context of mobile internet" Decision support systems, 42(3), 2006, pp. 1819-1834. https://doi.org/10.1016/j.dss.2006.03.009

11. Lu J, Yao JE, Yu CS., "Personal innovativeness, social influences and adoption of wireless Internet services via mobile technology" The Journal of Strategic Information Systems, 14(3), 2005, pp. 245-268. https://doi.org/10.1016/j.jsis.2005.07.003

12. Nysveen H, Pedersen PE, Thorbjørnsen H.," Intentions to use mobile services: Antecedents and cross-service comparisons" Journal of the academy of marketing science, 33(3), 2005, pp. 330-346. https://doi.org/10.1177/0092070305276149

13. Verkasalo H, López-Nicolás C, Molina-Castillo FJ, Bouwman H., “ Analysis of users and non-users of smartphone applications" Telematics and Informatics, 27(3), 2010, pp. 242-255. https://doi.org/10.1016/j.tele.2009.11.001

14. Kim SY, Lee SH, Hyung HS., "A Study of the Factors Affecting Adoption of a Smartphone" Entrue Journal of Information, 10(1), 2011, pp. 29-39.

15. Kim SG., "Influences of user environments and intrinsic features of smart phone on the perceived usability and receptivity," Ph.D Thesis, University of HongIk, 2009.

16. Park IG, Shin DH., "Using the Uses and Gratifications Theory to Understand the Usage and the Gratifications of Smartphone" The Korea Regional Communication Research Association, 10(4), 2010, pp. 192-225.

17. Wu JH, Wang SC., "What drives mobile commerce?: An empirical evaluation of the revised technology acceptance model" Information \& management, 42(5), 2005, pp. 719-729.
18. Wu JH, Wang SC, Lin LM., "Mobile computing acceptance factors in the healthcare industry: A structural equation model" International journal of medical informatics, 76(1), 2007, pp. 66-77. https://doi.org/10.1016/j.ijmedinf.2006.06.006

19. Youm DS, Yu SY., "A Casual Structure Analysis of Intention for Continuous Use of Smart Phone Reward Application based on Technology Acceptance Model(TAM)" International Journal of Advancement in Computing Technology, 5(13), 2013, pp. 323-329.

20. Yu SY, Kim JH., "Use of motivations, benefits and loss factors effect on recommendation of reward application" Korean Journal of Consumer and Advertising Psychology,15(2), 2014, pp. 279-306. https://doi.org/10.21074/kjlcap.2014.15.2.279

\section{AUTHORS PROFILE}

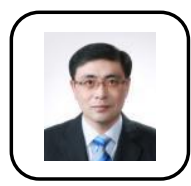

Yu, Seung-Yeob, February 1996: Chung-Ang University (Doctor of Advertising Psychology), 1997 present: Professor, Department of Advertising and Public Relations, Namseoul University, 2011-2012: President, Korean Society for Consumer and Advertising Psychology. 2020-2021: President, Korean Society of Consumer Studies. 